TAPROBANICA, ISSN 1800-427X. November, 2020. Vol. 09, No. 02: pp. 242-243, pl. 69.

(C) Research Center for Climate Change and Department of Biology, Faculty of Mathematics \& Natural Sciences, University of Indonesia, Depok 16424, INDONESIA.

http://www.taprobanica.org/

https://doi.org/10.47605/tapro.v9i2.241

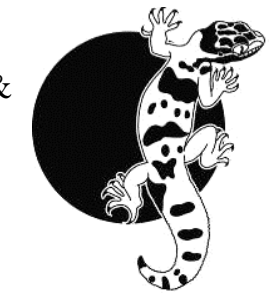

\section{On a gazelle eating a dove at Dubai Desert Conservation Reserve}

The Dubai Desert Conservation Reserve (DDCR) is a $225 \mathrm{~km}^{2}$ natural reserve in the Emirate of Dubai in the United Arab Emirates. It was established in 2002 and comprises some 5\% of the Emirate of Dubai's total landmass (DDCR 2020). It is home to many species of fauna and flora, including introduced Arabian mountain gazelles (Gazella gazella). There is thick vegetation within the reserve and some parts of the surrounding desert areas. Majority of the trees in DDCR were planted in 1999 or afterwards. There is a regular water supply provided for every tree except for fire bush Leptadenia pirotecnia (Family Apocynaceae), which is able to absorb moisture from mist and fog. The main vegetation consists of trees such as Prosopis cineraria (Family Fabaceae), Vachellia tortilis (Fabaceae), Ziziphus spinachristi (Rhamnaceae), Aerva javanica (Amaranthaceae), and Vachellia nilotica (Fabaceae). Gazelles at DDCR usually feed on the leaves, buds and fruit of these plants, and most of the time they are to be found in this thick vegetation. When leaves and pods fall to the ground the gazelles quickly eat them. There are many feeding stations at DDCR, but some individual gazelles never visit them. As well as the Arabian mountain gazelles, other common grazers at DDCR, include Arabian sand gazelle, G. marica, and Arabian oryx, Oryx leucoryx. In this specific location $G$. gazella is the most common and usually numbers around 100 individuals. All these grazers were reintroduced after their local extinctions due to hunting. Initially 24 Arabian mountain gazelles and 43 Arabian oryx were introduced in 1999, and the current populations reached 600 mountain gazelles and 800 oryx during last two decades. The adult grazers have no predators; scavengers include Arabian red fox, Vulpes v. arabica; Rüppell's sand fox, V. rueppellii; and lappetfaced vulture, Torgos tracheliotos.
On 9 March 2020 around 16:40 h, one of us (PLM) observed a group of four adult Arabian mountain gazelles near the research centre building at DDCR. Three of them were males and the fourth was a female. At that time the air temperature was $32^{\circ} \mathrm{C}$. One of the males appeared with a bird in its mouth (Fig. 1A). It was freshly caught as the bird's movement indicated that it was moribund, but not dead. The gazelle was trying to tear the skin of the bird using its teeth. We also observed it to use its forelimb to hold the prey while tearing off the meat using its mouth, like an experienced hunter (Fig. 1B). However, we also noticed that it was difficult for the gazelle to tear the skin and break the meat into pieces, because it shook the prey, nodding the head (Fig. 1C). Obviously this is due to the absence of carnassial teeth that carnivores use to shear flesh. Therefore it was munching rapidly using its anterior incisors to cut the skin and finally removed the feathers (Fig. 1D). It tried several times to dig into the meat using the snout and we observed blood on the gazelle's snout, as well as on the ground. The gazelle really ate the flesh of its prey, and seemed to enjoy it (Fig. 1F). Ultimately, it ate almost $1 / 3$ of the prey meat; however we observed that the head and legs of the prey were not damaged. After five minutes, another male of that group tried to steal the prey, upon which the first gazelle left the carcass and ran away. The invading gazelle chased the first, but did not pick up the bird. The other gazelles followed the two running away and disappeared. Within five minutes, none of the gazelles had returned. The prey bird was identified as Eurasian collared dove, Streptopelia decaocto, a very common bird at DDCR. Other common birds at DDCR include laughing dove, Spilopelia senegalensis; rock dove, Columba livia; grey francolin, Francolinus pondicerianus; common myna, Acridotheres tristis; Arabian babbler, Turdoides squamiceps; red-vented bulbul, Pycnonotus cafer; and white-eared bulbul, Pycnonotus leucotis. During the predation, we observed several other collared doves on the 
ground within a few meters, as well as in trees. This bird is an easy catch for gazelles as it is commonly found on the ground in high numbers. There are over 500 individuals in the vicinity of the research centre and resort at DDCR. Although rarely documented, several incidents of meat eating in antelopes and deer (Cervidae) have been recorded from different regions in the world. For example, a group of researchers spotted a white-tailed deer, Odocoileus virginianus, chewing on a human rib during a study aimed at examining how human remains decompose in the wild (Ross 2017). In addition there are records of white-tailed deer catching and eating fish (Olson 1932, Shea 1973, Case \& McCullough 1987), feeding on insects (Shaw 1963), preying on nestling song birds (Thompson et al. 1999, Pietz \& Granfors 2000), even eating live birds caught in a mist net in Canada (Allan 1978), as well as dead rabbits. In addition to white-tailed deer, cattle (Bos taurus) preying on grassland bird nests (Nack \& Ribic 2005); red deer (Cervus elaphus) preying on seabird chicks (Furness 1988); sheep, Ovis aries, eating seabird chicks, have all been observed. Even domestic rabbits, Oryctolagus cuniculus, have been recorded consuming carcasses (Clauss et al. 2016). Although most of the reported cases are of ungulates feeding on dead animals or bird eggs or chicks, this is a clear case of predation by a gazelle on a dove. Ross (2017), Furness (1988), and others hypothesised that herbivores may eat flesh because they lack minerals such as phosphorous, salt, and calcium, especially in the winter months when plant life is scarce. Furness (1988) stated that it is presumably a response to mineral deficiencies in the vegetation, concluding that it is how red deer get the dietary boost necessary to grow their antlers. However, Furness (1988) speculated that it may only occur in rare situations where ruminants feed on mineral-deficient vegetation in which there are dense colonies of ground-nesting birds. We believe this is the same for gazelles living in deserts, in this case preying not on ground-nesting birds, but on doves that spend a lot of time on the ground. It is also possible that gazelles in this arid desert environment where water is scarce have adapted to carnivory as a source of moisture.

\section{Acknowledgement}

We thank Tamer Ali Khafaga (Conservation Research Manager), Greg Simkins
(Conservation Manager), and Moayyed Sher Shah (Conservation Officer) at DDCR for their support.

\section{Literature cited}

Allan, T.A. (1978). Further evidence of whitetailed deer eating birds in mist nets. BirdBanding, 49: 184-184.

Case, D.J. and D.R. McCullough (1987). WhiteTailed Deer Forage on Alewives. Journal of Mammalogy, 68 (1): 195-198.

Clauss, M., A. Lischke, H. Botha, and Jean-Michel Hatt (2016). Carcass consumption by domestic rabbits (Oryctolagus cuniculus). European Journal of Wildlife Research, 62: 143-145.

DDCR (2020). Dubai Desert Conservation Reserve. Al Maha, a Luxury Collection Desert Resort \& Spa, Dubai <https://www.ddcr.org>. Retrieved on 14 March 2020.

Furness, R.W. (1988). Predation on ground-nesting seabirds by island populations of red deer Cervus elaphus and sheep Ovis. Journal of Zoology, 216 (3): 565-573.

Nack, J.L. and C.A. Ribic (2005). Apparent predation by cattle at grassland bird nests. Wilson Bulletin, 117: 56-62.

Olson, S.F. (1932). Fish-eating deer. Journal of Mammalogy, 13:80-81.

Pietz, P.J. and D.A. Granfors (2000). White-tailed deer (Odocoileus virginianus) predation on grassland songbird nestlings. The American Midland Naturalist, 144 (2): 419-422.

Ross, D. (2017). Never Before Seen: Deer Spotted Eating Human Bones. Available online at <https://www.nationalgeographic.com/news/2 017/05/deer-eating-human-forensics-decompo sition/>. Retrieved on 14 March 2020.

Shaw, H. (1963). Insectivorous white-tailed deer. Journal of Mammalogy, 44: 284.

Shea, D.S. (1973). White-tailed deer eating salmon. The Murrelet, 54: 23

Thompson, F.R. III, W. Dijak, and D.E. Burhans (1999). Video identification of predators at songbird nests in old fields. Auk, 116: 259264.

Submitted: 15 June, Accepted: 07 November 2020 Section Editor: Lee Harding

P.L. Madurapperuma ${ }^{1} \&$ A.A.T. Amarasinghe ${ }^{2}$

${ }^{1}$ Nature Explorations \& Education Team, No: B-1/ G-6, De Soysapura Flats, Moratuwa, Sri Lanka E-mail:wildmplzoo@gmail.com

${ }^{2}$ Research Center for Climate Change, Kampus UI, University of Indonesia, Indonesia Email: thasun@rccc.ui.ac.id 


\section{Plate 69}
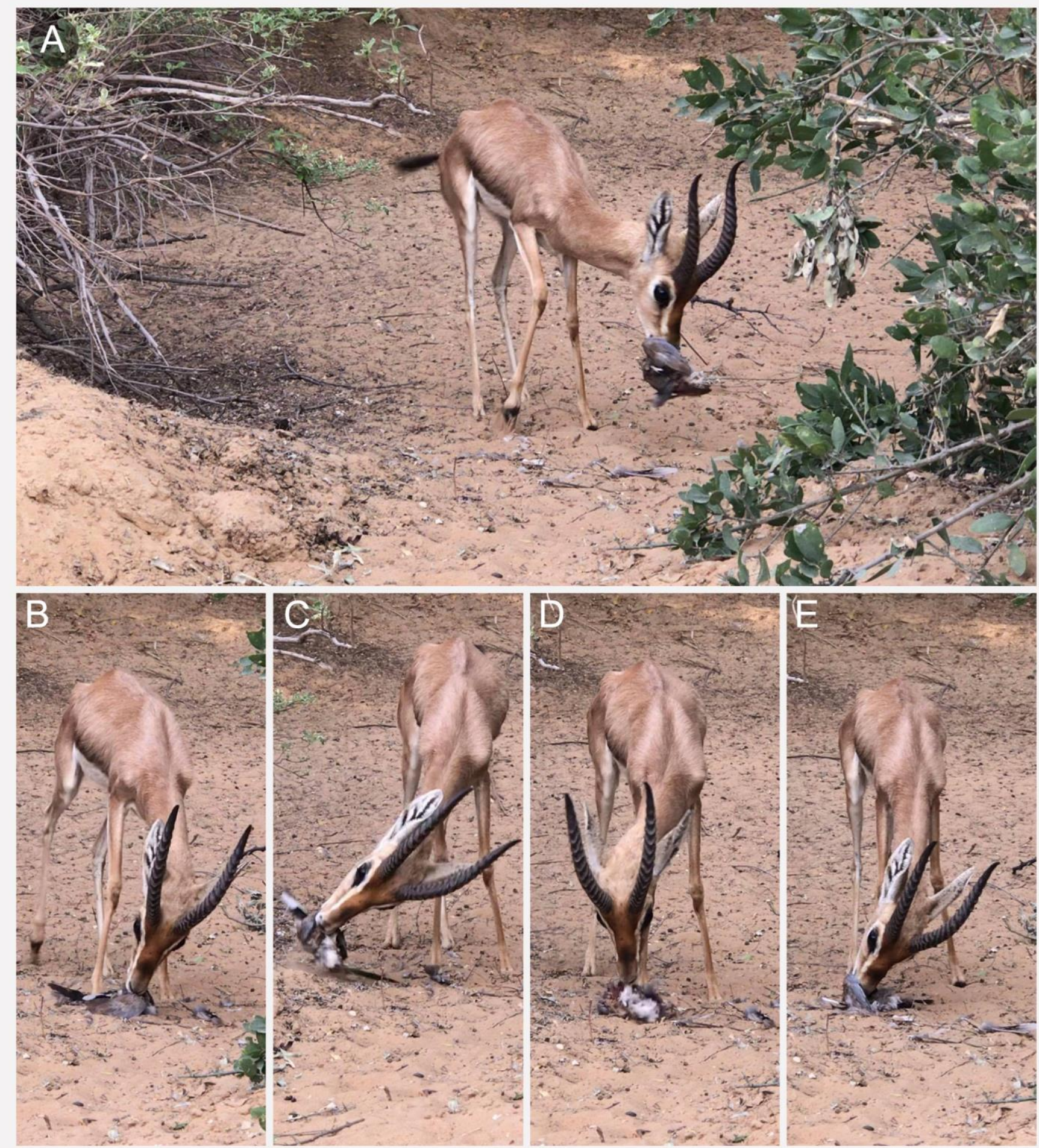

Figure 1. Arabian mountain gazelle, Gazella gazella feeding in Eurasian collard dove, Streptopelia decaocto at the Dubai Desert Conservation Reserve, United Arab Emirates: the gazelle (A) with a dove in its mouth; (B) catching its prey from its forelimb to tear the skin from its teeth; (C) shaking the prey nodding head; (D) chewing and removing the skin; and (E) using the incisors to eat the flesh. 